University of Nebraska - Lincoln

DigitalCommons@University of Nebraska - Lincoln

Faculty Publications: Department of Teaching, Department of Teaching, Learning and Teacher Learning and Teacher Education

Education

2012

\title{
Are the challenges and opportunities in contemporary diverse classrooms being met?
}

\author{
Loukia K. Sarroub \\ University of Nebraska-Lincoln, Isarroub@unl.edu \\ Lisa Patel Stevens \\ Boston College
}

A. Jonathan Eakle

The Johns Hopkins University

Follow this and additional works at: https://digitalcommons.unl.edu/teachlearnfacpub

Part of the Bilingual, Multilingual, and Multicultural Education Commons, and the Curriculum and Instruction Commons

Sarroub, Loukia K.; Stevens, Lisa Patel; and Eakle, A. Jonathan, "Are the challenges and opportunities in contemporary diverse classrooms being met?" (2012). Faculty Publications: Department of Teaching, Learning and Teacher Education. 128.

https://digitalcommons.unl.edu/teachlearnfacpub/128

This Article is brought to you for free and open access by the Department of Teaching, Learning and Teacher Education at DigitalCommons@University of Nebraska - Lincoln. It has been accepted for inclusion in Faculty Publications: Department of Teaching, Learning and Teacher Education by an authorized administrator of DigitalCommons@University of Nebraska - Lincoln. 


\section{Are the challenges and opportunities in contemporary diverse classrooms being met?}

POINT: Loukia K. Sarroub, University of Nebraska-Lincoln

COUNTERPOINT: Lisa Patel Stevens. Boston College

\section{OVERVIEW}

Cultural diversity suggests the multiple and different ways groups of people share attitudes, perceptions, values, and practices. This overview examines a variety of the typically identified groups who share these four dimensions of culture. Although convenient for organizing this introduction, there are often significantly overlapping aspects between these major groupings, and indeed, there are infinite variations of cultures and many minority alliances whose listings are far outside the scope of a single chapter.

In many regions of the United States prior to and during the 20th century, a visible marker that signified cultural differences was racial categorization. Although there have been different racial categories used for various purposes, such as the identification of Asian Americans during World War II for internment by the U.S. government, the most salient racial division has been that between black and white, which was a catalyst for the civil rights movement. These lines of race were remnants of other cultural divides, such as those between the North and South or master and slave. Even now, what is often described as racial barriers marking these black and white historical divides remain apparent such as in how many of the urban centers on the Eastern Seaboard are organized and separated. These geographic zones have enormous effects on how public schools are constituted.

Other salient cultural divides in the United States are indicated through language, which is likely the most intimate aspect of cultures, as addressed 
in the point essay of the present chapter. Notwithstanding the numerous languages that became part of the United States during the great wave of immigration of the early 20th century, until recent years, a principal border between languages was found in areas occupied by people who had at one time or another been touched by various colonial land acquisition practices, such as those embedded in the histories of Texas and Arizona. In fact, in North America there are dozens of indigenous languages situated alongside colonial ones, such as Spanish, French, and English. In this vein, cultural diversity is often signified through infinite variations of languages, such as the southern drawl of English or among those whose native countries are Spain, Argentina, and Mexico who pronounce Spanish words differently. It is also this variation that marks the ongoing debate between what has been defined as Ebonics or African American Vernacular English (Delpit \& Dowdy, 2002). While the cultural differences among people who share a language or its variation are immense, in the United States they are often lumped into umbrella categories, such as Hispanic.

Economics and class separate cultural groups in the United States as well. During the Great Depression of the 1930s, material resources were placed under greater oversight of and by the federal government to, in part, assure some degree of economic stability or social security, and gradually during modernity, schools became increasingly supported by governments. In the wake of the more recent Great Recession, economic divides have been a source of much discussion, especially as people have lost their homes while corporations have reaped what are for many people inconceivable profits. These factors not only affect personal lives but also public school cultures. For instance, when the so-called housing bubble burst and home prices declined, so too did the property tax income of states and counties. As a result, educational funding diminished in many regions of the country, which subsequently has led to lost human and material resources for public schools-many of which were already grossly different in what they were afforded due to regional class differences. The long-term effects of these economic issues on schools, teachers, and children are yet to be seen.

The cultures marked by different economic classes is indicative of cultures of politics, which are dividing lines that are visible in recent multimedia maps of voting trends that show red Republican zones alongside the blue ones of Democrats. Less dominant are the cultural values of other political groups, such as the Libertarian Socialists and Green Party, and the values of growing numbers of independent people who do not wish to be affiliated with a political party or the scores of citizens who seemingly do not value the U.S. electoral process and thus choose not to participate in it. Like economics, political capital and power exercised by various groups greatly influence education policy and the values, attitudes, and practices of school cultures. 
Associated with debates of salient and different political values and perspectives, at least as early as Thomas Jefferson's famous letter to the Danbury, Connecticut, Baptist Convention in 1802, is separation between church and state in the United States. Yet, the cultures of religions have had enormous effects on U.S. schooling - a topic taken up in an entire volume of the present book series. Values and beliefs held by religious cultures, such as those found in the Ten Commandments and how the universe was purportedly created or evolved, are some of the most publicized and debated issues in schools and courtrooms of certain areas of the United States, especially the Bible Belt.

In addition, gender issues and cultural values commonly ascribed to gender subjects have influenced, and will continue to influence, education and other social and political practices in the United States. For example, it was only during recent decades that women gained access to education in certain professions and ranks, and they remain disproportionately underrepresented in major corporate positions, the natural sciences, and so forth. On the other hand, men are a minority in occupations such as those of nursing and public school classroom teaching. Nonetheless, even what had seemed to be a clear categorical division between male and female sexes has become increasingly blurred. In this vein, sexual preferences, transgender ways of being, transsexuality, and so forth have increasingly become topics of education conversations.

Education in itself results in the formations of various cultures, such as the culture of schools, higher education, the academy, and so forth. Further, age, desire, and preferences influence the formation of other cultural groups, such as youth culture and popular culture, topics taken up in another chapter of the present volume (Chapter 13). Indeed, culture is most of all a multiplicity.

The following two essays underscore novel and powerful dimensions of the multiplicity of cultures and education. Unlike many of the essays in the present volume, both authors chose to write in the first person. This is not coincidental because culture is based on identifications-what allows one to articulate the "I" of group alliances and identity. In contrast, scientific writing style, such as that of the American Psychological Association (APA)which is the standard for much professional publication in education-typically pushes the author "I" to the side, which can give an inaccurate view of how subjectivity influences research and writing. Such narrative approaches, as shown in the subsequent essays, provide a space for subjects rather than simply objects and push against the academic canon. This also denotes the degree of reimagination that many people believe is needed for education research, policy, and practices - a theme that both authors share. Also a part of this reimagination is how language evolves, which is shown subsequently in how authors create neologisms to express ideas that are not part of the common lexicon. For example, "minoritized" is a word used in the counter- 
point essay to show how minority subjects are formed (see also Deleuze \& Guattari, 1975/1986).

In the point essay, Loukia K. Sarroub of the University of Nebraska-Lincoln uses vivid accounts of her research experiences with Yemeni Americans to show how the complexities of cultures and identities are too often misunderstood. Much of her focus is on how language works in different spaces and for various purposes. This is shown through her own imaginative writing and her call to find ways to reach beyond stereotypes and visualize different ways for us to transact in and with education communities and beyond. Sarroub concludes that the answer to the question of whether the challenges and opportunities in contemporary diverse classrooms being met is mixed. She feels that schools have good intentions and have adequately addressed the history and social constructions of minority groups but undermine the links between language and culture, how language constitutes those we talk and write about and those we represent in textual and visual ways.

Pushing against the grain in the counterpoint essay that follows, Lisa Patel Stevens from Boston College responds in the negative. Taking a critical pedagogy position, she points out how past education practices that seemingly celebrate diversity are often superficial ones, and she offers concepts and practices that can move education toward a valorization of diversity to extend present views of culture. She suggests that education needs to engage teachers and students in topics such as the struggle for legitimacy, xenophobia, protectionism, and global economic power. Valorization, Stevens contends, requires teachers and students to move beyond foods, fashions, and festivals to discuss how we should transact with and resist laws of exclusion, how such laws erode an inclusive social order, and what more equitable edicts and practices would promote.

\author{
A. Jonathan Eakle \\ The Johns Hopkins University
}




\title{
POINT: Loukia K. Sarroub University of Nebraska-Lincoln
}

\begin{abstract}
$A$ $\mathrm{s}$ I begin this essay, I am reminded of Edmond LaForest, a prominent Haitian poet who could not make sense of his colonized identity as either French or Haitian and who in 1915 stood on a bridge, "tied a French Larousse dictionary around his neck, and leaped to his death. This symbolic, if fatal, grand gesture dramatizes the relation of language and cultural identities" (Kramsch, 1998, p. 65), of the communities in which we live, and the communities in which we imagine we would like to live. LaForest's death acquired new meaning when recounted in 1985, at a time when linguistic and cultural rights were starting to be viewed as basic human rights. This has been especially true in light of the hegemonic spread of English around the world and its propagation of global consumerist ideologies.

By way of quick example, think of the following: American English is often characterized by metaphors linking time to money: We "spend" time-we don't pass the time as Spanish speakers and other indo European language speakers do; we say "time is money," "the buck stops here," "put your money where your mouth is." It's no wonder that our language and culture of time/money make us eat faster and everywhere (hence the now-worldwide phenomenon of fast food on the go and in the car) or that we argue about the comparative values we use to explain our choices - that it's not the length of time we spend with our children but the quality of time that counts. While I do not focus this essay on the linguistic imperialism of English or the French, for that matter, my point in sharing LaForest's sad fate is to show the significance of language and culture in connection with identity and education and in connection to the communities we construct, sustain, and imagine for ourselves.
\end{abstract}

\section{STEREOTYPE AS COMMUNICATIVE PRACTICE?}

As we individually and collectively imagine the communities within which we would like to live, considering the theme of the present essay is especially appropriate given the current global and political situation and the ways in which various discourse communities in the United States and abroad interact. The notion that the opening of minds might move us beyond stereotypes is an intriguing proposition. Immediate questions that spring to mind are as follows: How do we do this? How do we open minds? How do we become aware of the stereotypes we share? How do we move beyond them? 
It seems to me that first there must be a critical awareness of how people, institutions, and governments interact with one another. How are thoughts, ideas, mandates, policies, laws, and traditions communicated? How are power and authority negotiated, and who benefits from these negotiations? By beginning with these questions, not only do we begin to open minds but we also begin to open hearts, for we do live in a world where there exists extreme miscommunication along with other extremes such as poverty, disease, and limited educational opportunities.

For example, some years ago I conducted fieldwork in a Yemeni American community in the Detroit, Michigan, area. As part of my fieldwork, I would often accompany the youth in the area on their various errands. On one occasion, I went with Asya and her father to buy new tires for their car. We left the relative safety of the neighborhood, in which everyone knew everyone else, and ventured out into the business area of Dearborn, Michigan. On our arrival at the tire shop, the receptionist took one look at Asya, who wore a head scarf and long dress, and at her father, who had a mustache. She proceeded to ignore them completely after she caught a glimpse of me in the background. She crooked her finger at me, and said, "Are you with them? What do they want?"

Sociolinguists might spend hours analyzing this contextual scene, its paralinguistic elements, and how this receptionist's questions embody the power dynamics at play. Basically, as anthropologist Michael Agar might say, the receptionist displayed a \#1 mentality, wherein anyone who looks different from the expected norm cannot communicate and more importantly cannot think as well. Agar (1994) also argued that Americans are often guilty of the \#1 mentality, in part because most do not speak a language other than American English and therefore their understanding of cultural and imagined realities are confined to the values expressed by their language. Now Asya and her father, who are Americans, understood the situation within seconds. They asked to see the supervisor, explained to him what had occurred, told him that the receptionist was disrespectful, and then said that they would go elsewhere to look for tires.

The tire shopping example illustrates how complicated and complex the building of community is. We might begin with becoming critically aware of how we use language to communicate with others, but the stereotypes linger and can suffocate any hope for understanding. Sociolinguists define stereotype as the "conventionalized ways of talking and thinking about other people and cultures" (Kramsch, 1998, p. 131). Scholars of language do not impose a negative or positive value on stereotypes because one universal that characterizes all languages is that speakers tend to find the most efficient ways to express themselves, and this means that all speakers categorize the world in various ways for the sake of efficiency. 
Outside of sociolinguistics, a stereotype connotes negativity and creates a distance between us and them, between our culture and their culture.

Among the Yemeni American youth I studied, I found plenty of stereotypes about what it meant to be American or Yemeni, or Arab, and at the core were questions of identity and what Benedict Anderson calls "long distance nationalism" among immigrants where the present-day homeland is more imagined than it is real. Stereotypes may index a truth at a given moment, but because "cultures are fundamentally heterogeneous and changing... and are a constant site of struggle for recognition and legitimation" (Kramsch, 1998, p. 10), stereotypes create a false reality that gives credence to the myth that a culture is static rather than dynamic, that people cannot think outside of the categories they've constructed to explain the world as in the case of the tire shop receptionist.

While stereotypes do exist, it is also clear that schools continuously evolve to address them, often struggling to define what legitimate practices might be when linguistic, ethnic, cultural, socioeconomic, and/or national diversity is represented in the student body. For example, in one high school in Dearborn, Michigan (Sarroub, 2005), administrators and teachers went to great lengths to address miscommunication between the school district and the Arab community in southeastern Michigan, differences in participation and interaction among their European American and Yemeni American students, demands for religious accommodations, and gendered and cultural accommodations for dress in various classes, etc. The majority of the staff were white middle-class teachers who for the first time in the inception of the high school were teaching a population of Yemeni American and Yemeni youth quite unlike themselves. The curriculum was revisited; lunch menus were debated; PE classes were assessed for appropriateness; and more importantly, teachers were positioned and positioned themselves in favor of accommodating diversity or not in favor of accommodating diversity. Teachers talked about treating everyone in the same way, thus buying into a classical liberalism that did not address individual and collective differences. The youth themselves lobbied for change and reform in the school to address religious practices. My point is that there is potential for change when communicative practices are put in place to foster such change, even when the challenges seem insurmountable.

\section{PARTICIPATION IN COMMUNITIES OF PRACTICE}

How do we move beyond stereotypes? In the past several years, many of us have paid close attention to the presidential campaigns of George W. Bush and John Kerry and then John McCain and Barack Obama. Their interactions and advertising campaigns have been as much about lan- 
guage use as they have been about the war and devastation in Iraq, the domestic economy, health care, and other issues. For example, Bush admitted that Austrian native Arnold Schwarzenegger is more articulate than he (Bush) is in English, and the media resoundingly endorsed Kerry as the more effective speaker and communicator. The candidates' individual messages about what they "plan" or imagine the United States and the world to be have also been cast differently, with one candidate using metaphors of fear, safety, and war and the other focusing on safety, communication, decreasing the deficit, and global community. The candidates argued until the elections, and their arguments gave evidence for another problematic metaphor in American English: Argument is war. For example, American English speakers say, "Your claims are indefensible," "He attacked what I said," "She was right on target," "OK, go ahead, shoot," "He'll wipe you out," "I won that point." The United States is a competitive nation, and its language illustrates this. One might say that there is little subtlety in our words or in the actions they express. The advent of Obama in national politics disturbed ideologies of competition because his discourse advanced notions of unity and togetherness.

In 1971, in the song "Imagine," John Lennon sang about imagining a world without countries, a place with no killing and dying or religion, a place where people live peacefully. His dream in the song of a people living as one is a powerful political precedent and educational one. In many places in the United States, schools have figured out or are figuring out how to engage students in learning regardless of the teachers' or students' backgrounds. This is an important aim of equitable and accessible education for all.

I've always liked Lennon's song even though I don't necessarily advocate for no countries. After all, if we were all the same we wouldn't have much to talk about today. "Imagine" provokes a set of images that allow us to speak of a world that is more open, where people share, where there is no war. As idealistic as Lennon's song sounds, it reminds me of Harvard educator Marcelo Suarez-Orozco's (2001) definition of globalization. He defined it as follows:

... as a process of change, generating at once centrifugal (qua the borders of the nation state) and centripetal (qua the post-national) forces that result in the deterritorialization of important economic, social, and cultural practices from their traditional moorings in the nation state, (p. 347)

According to Suarez-Orozco, large scale immigration is a world issue and is transforming Africa, Asia, Europe, and the Americas: "Roughly $30 \%$ of Frankfurt's population is immigrant. Amsterdam by the year 2015 will be 50\% immigrant" (p. 349). Leicester, England, is the first city 
in Europe where "whites" will no longer be the majority. Japan needs immigrant workers to maintain economic vitality. Africa has the largest numbers of refugees in the world. In the United States, the fastest growing sector of the child population is immigrant children (SuarezOrozco, 2001). The world is changing, perhaps not becoming one as in Lennon's song, but significantly changing such that linguistic, social, and cultural practices have more immediate consequences and will be called into question.

My own research is concerned with what it means to be successful in public schools and how American-born and immigrant youth become literate in and out of school. I study why it is that youth in high school cannot read and how institutions such as schools, government, families, and community organizations accommodate one another. I've found that in general there is no question that families and schools have the best intentions with regard to their children and students, but they are not necessarily prepared or educated enough to understand one another and the systems they inhabit, especially in the Midwest, where non-Western immigration is a relatively new phenomenon. The reality of public education today is that it is fraught with social issues that influence the ways in which students learn and communicate. Further, as Davis Guggenheim pointed out in his 2010 documentary, Waiting for "Superman," the social problems experienced by both schools and families exist within an organizational infrastructure meant to deal with an industrial rather than postindustrial economy. For example, the United States has a decentralized school system "financed mainly by local property taxes [that] ensures the perpetuation in schools of the local social class structure and local ethnic and racial distribution" (Kramsch, 1998 , p. 83). Further, in 1998, alarming trends were reported by a national study among 20,000 randomly selected U.S. teenagers, and here I quote directly from the report:

Foreign-born youth experience fewer physical health problems, have less experience with sex, are less likely to engage in delinquent and violent behavior and are less likely to use controlled substances than native-born youth. .... Among foreign-born youth, statistical analysis showed the longer the time since arrival in the U.S., the poorer was the adolescents' physical health and the greater the likelihood of engaging in risky behaviors. (Migration Dialogue, 1998, p. 3)

The United States is certainly the land of economic opportunity and education, but the questions remain for whom and how? In the past several years, we've witnessed worldwide divisiveness, and neoconservative (in the United States and Europe) and fundamentalist movements (Mideast and Southeast Asia) that largely stem from cross-cultural miscommunication about cultural and religious norms, especially in immi- 
grant communities; the failure of educated individuals to take humanitarian and proactive steps to build rapport rather than to destroy; and the further corruption by consumerist ideologies of socially minded welfare systems, such as the lack of universal health care for citizens or anti-immigration laws that favor some populations over others.

Going beyond the stereotypes to create our imagined communities requires critical awareness and a collective enactment of communicative practices within our communities. Communicative practices reflect "institutionalized networks of relationships, denned by nationality, family, school, workplace, professional organization, religious organization, and all their expected roles and statuses, values, beliefs, and ideologies" (Kramsch, 1998, p. 83). In the early 1990s, a new line of thinking emerged, redefining what community means. Going beyond the idea of community as a group with a common repertoire or shared codes, theorists Jean Lave, Etienne Wenger, Penelope Eckert, and Sally McConnell-Ginet suggested "communities of practice" defined as "an aggregate of people who come together around mutual engagement in an endeavor" (Eckert \& McConnell-Ginet, 1992, p. 464). The idea is that people are engaged together in some project and that all of us in one way or another, as Lave and Wenger (1991) argued, are "legitimate peripheral participants" in these projects. In other words, we are all constantly learning new ways of speaking and interacting as we enter into collective endeavors, no matter how far we are from communities in which our participation is peripheral or minimal.

\section{CONCLUSION}

I began my essay with the sad account of the Haitian LaForest's real and symbolic death by French dictionary, a death reflecting the ambiguity of an occupied identity in flux, where a sense of community did not seem possible. Whatever layers of disillusionment pervade our lives, we can still productively imagine and enact communities that reflect a generosity of spirit both in action and talk. This edited volume, including the essays of Jonathan Eakle and Lisa Stevens, testifies that many, if not all of us, have cast aside and reinvented ourselves, the communities, and the nations to which we belong. Are the challenges and opportunities in contemporary diverse classrooms being met? Many educators have good intentions about thoughtfully representing all and everyone, but euphemistic expressions and the emergence of extreme politically correct talk have served to hide the tapestry of diversity. Schools seem to have adequately addressed the history and social constructions of legally recognized minority groups while simultaneously undermining the links between language and culture, how language constitutes those we talk and 
write about and those we represent in textual and visual ways. However, honoring the difference and diversity within and among human beings and the communities we imagine and eventually enact will be an ongoing project in the 21st century.

\section{COUNTERPOINT: Lisa Patel Stevens Boston College}

Twork with recently immigrated youth living in Boston. As I write this es1 say, these youth are in the midst of preparing for the rapidly approaching school year. They are perhaps purchasing school supplies; mapping the public transportation route to the high school that they will attend; savoring the last few days of their summer break from schooling; or if they have not yet attended school in the United States, wondering what it will be like here, what will be expected of them, and how they will manage to get by as newcomers. At the same time, their teachers, mostly white, female, and middle class, are working through existing curricular frames and pedagogical approaches designed to promote school-defined success. I mention these youth and their teachers because in answering a question such as the one of the present essay, being specific helps. It helps keep us centered on who education is for explicitly and implicitly, how it must have disserved and might serve diverse populations of youth, and where past efforts have faltered. From these critical points, we as educators might assess how well our education work is being done.

While these people are propping for the start of a new academic year in 2010, there were a few political issues dominating U.S. media worth mentioning, particularly in relation to immigrant populations. First, there was the highly debated and hotly contested proposal to build an Islamic Cultural Center about four blocks from the former site of the World Trade Center towers in New York City. Some protested the location of this center as disrespectful to the memories of those who died during the terrorist attack of $9 / 11$. Others bemoaned these protests for a lack of regard for religious freedom and free speech afforded through the U.S. Constitution. Alongside the Islamic Center debates, the state of Arizona was fighting federal government intervention to stop two proposed pieces of legislation that target immigrant populations: one that obligated police officers to question those who appear to be in the country without government sanction about their legal status (Support Our Law Enforcement and Safe Neighborhoods Act, 2010) and another proposal that pro- 
hibited ethnic studies courses in Arizona's schools (Prohibition of Seditious Ethnic Studies Act, 2010). In the point essay to this question, Loukia K. Sarroub drew in examples of communities, institutions, and people outside of schools, underscoring the symbiotic relationship between people, schools, and societies. These social contexts echo in the explicit curricula of the United States, including multiculturalism, and in the implicit absences and silences of white privilege and long histories of education as colonization. To put it mildly, diversity issues are anything but a comfort zone in the American landscape.

I must respond to the question in this chapter of meeting the challenges and opportunities of contemporary diversity in light of the surrounding and constitutive historical, social and political contexts of education. These issues and events, such as the ones I mentioned earlier, provide just some of the necessary foundation for the question of whether today's schools are meeting the challenges and opportunities. Because schools are situated in society and also reflect the society that surrounds them, they have the potential to engage with the ideas, values, and actions of that society. Also schools have the obligation to prepare students for these surrounding contexts. It is particularly in light of preparing racially minoritized and white students for social contexts that I answer an emphatic no to the question of whether schools are adequately meeting the challenges and opportunities of a diverse contemporary society.

\section{HOW WILL OUR OUTCOMES BE MEASURED?}

To meet the challenges and opportunities of diversity appropriately, it is usually taken to simply mean that schools should reflect, in their curricula, materials, and perhaps their pedagogy, a diverse student and societal population. Not only are U.S. schools not achieving this goalgiven the present contextual backdrop and the history of our country's social reproduction of class, race, cultural, and gender inequities through schooling-this particular goal is an abysmally low one. It obligates schools, which are mostly staffed by white middle-class professionals, to represent diversity, which is often talked about in and of itself, but not necessarily the diversity found in schools and classrooms. There are three potential and co-influential locations where this representation can occur: pedagogy, assessment, and curriculum. Teaching and learning, or pedagogy, in the United States has remained a largely teacher-centered, banking-like approach (Freire, 1970), through which teachers seek to deposit traditional knowledge into the assumed empty or miseducated minds of students by use of their positions as authority figures. In turn, students are evaluated, with increasingly high-stakes ways for them and their teachers, via linear, standardized assessments that preserve knowledge 
as static and neutral. In short, pedagogy and assessment remain largely reflections of white middle-class cultural practices.

The most frequent location of any kind of representation of diversity is in some curricula but not all curricula. The historical and social contexts of diversity in math and science education have been, and remain to be, all but absent from core standards movements (National Black Education Agenda, 2010). In an English class, though, you might find a section in the textbook entitled something like "Global Voices," and see entries taken from authors such as Martin Luther King, Jr.; Zora Neale Hurston; Sandra Cisneros; and Amy Tan. While these are outstanding authors who have much to lend to the social and literary education of today's youth, the sprinkling of their work in a largely Euro-centered textbook amounts to merely a symbolic representation of diversity. Furthermore, this diversity is not necessarily reflective of the constituents in the school or community. Add to that mix that much of this literature is mainly taught by teachers who come from different home cultures than these authors; who themselves are the products of a banking model of education steeped in Eurocentric curricula; and the inclusion of these authors' works usually does not include a deep understanding of the social contexts of their lives, the effect of their work on the past and present, and how their works might represent different worlds than those represented in canonical texts. Without this kind of engagement, a more typical cursory engagement with excerpts of great works, amounts to merely token symbolization, one that serves to center and legitimate the central white male European authors who make up the canon (Moreton-Robinson, 2008).

Such token symbolic representation, where only a few persons, at best, are taken to represent entire groups, is actually more corrosive than it is helpful to the edification of diverse student populations. Students learn, through the symbolic smattering of culturally diverse referents, that diversity is ancillary, an afterthought that ironically works to more firmly center European-delineated contributions to American thought, history, and events and easily subsumed under a few taken to represent a diverse many. In its worst moments, multiculturalism is manifested in a limited "foods, fashions, and festivals" approach where cultures are reduced to visible token symbols meant to stand for the collective, contested, and complicated histories that are endemic to all peoples. For students from nondominant class, ethnic, and gender backgrounds, they mistakenly learn that they, in turn, must also be ancillary - or at best complementary - but certainly not central members in American schools and society.

When the focus is on the canonical curriculum of the American ruling class, schools lose the opportunity to engage with the ways in which diversity issues are being met in the larger society. More simply put, how 
does a short and disintegrated textbook section such as "Global Voices" help immigrant and native-born youth interact, for example, with vehement, and at times, violent protests to Islamic culture in the United States? When there is such token engagement with diversity, although it is in some senses gesturing toward diversity, we are ill-equipping children and youth to understand the vicissitudes of identity, group membership, and civil rights that are at the core of polemic debates such as that concerning the Islamic Cultural Center in New York City mentioned previously in this essay. Rather, the goal remains more one of how to maintain the traditional curriculum and pepper it with representations of diverse peoples, or assimilation. To actually engage with diversity as opportunity would require a different set of goals.

\section{MEETING DIVERSITY'S CHALLENGES AND OPPORTUNITIES}

Although a very common question in schools and other education institutions, the question that guides the present essay is an ironically sad reflection of the state of multicultural education in the United States. It reflects a cosmetic approach to multiculturalism that has marked efforts to revise Eurocentric curricula and pedagogy in public schools. Asking the question is often the beginning and end of attention to diversity that paradoxically reflects an all too common invocation of diversity as a challenge.

Multicultural education, as a movement and field of study, is built on the premise that American society is pluralistic and that education should serve this pluralism. A major goal of multicultural education is "to reform the school and other educational institutions so that students from diverse racial, ethnic, and social class groups will experience educational equity" (Banks, 1993, p. 25). However, multicultural education has most often taken this concept of equity to simply mean a superficial representation of cultural diversity. This manifestation is directly connected to the vast majorities of teachers and teacher educators coming from dominant Eurocentric backgrounds. Put simply, this response reflects far more of the shortcomings and miseducation of teachers and teacher educators than it reflects of the students in today's classrooms.

The goal of meeting the challenges of diversity most often seeks to position white educators with opportunities to provide culturally minoritized students cultural referents in curricula. In the end, it does nothing to interrogate or change cultural structures of power, thereby reifying existing power structures. Without a doubt, inclusive education that draws from a variety of cultures (e.g., ethnic, class, gender, and sexual identity) is a must for all students, but I aver that this goal is in some ways even more important for students from dominant, or majoritized, back- 
grounds. While some students have been miseducated to believe that their cultures are ancillary, other students have been simultaneously miseducated to believe that their cultures are inherently the smarter and more valuable contributors to society (Nieto, 2008). Rather than seek to represent the cultures in front of a particular teacher or school registrar, true diversity in education should seek to engage all learners in the active learning of knowledge as a multifaceted, contested, alive, and pliable process that can only come from various perspectives. In this sense, diversity is itself an opportunity, one that is essential to avoid monocultures of thought and practices, which ultimately lead to their demise. Ecologically speaking, a monoculture is the agricultural practice of producing or growing one single crop over a wide area. From a capitalist point of view, this is great. You make all the cogs and widgets that the machine needs to grow, harvest, and sell the single crop-efficiency at its smoothest. However, from a more longitudinal and deeper view of biodiversity and sustainability, monocultures are not such great things. Overproducing a single crop undermines the ability for any ecosystem, necessarily made up of different parts, to survive. Create a monoculture, and you may as well start making collectors' editions of calendars, because for that ecosystem, time is limited. Jared Diamond named monocultures as one of the four fundamental threats to biodiversity. E. 0. Wilson addressed overharvesting in his warnings against a system of five threats to biodiversity. And predating any European patterns of agriculture, indigenous communities in the Americas, the South Pacific, and Asia thrived on heterogeneous agricultural crops that fed back into the lands' abilities to produce foods appropriate to those climates.

For the immigrant youth I've been mentioning, of course, many educators would prefer that they be taught by teachers who understand and perhaps even reflect their backgrounds; learn about their own histories alongside the histories of other peoples; and who actively shape their curricula, pedagogy, and assessment practices to reflect themselves and their cultures. For immigrant youth and other youth from nondominant backgrounds, the inclusion of these cultural referents is but a partial start. This is the second aspect in which we are falling short of tapping the potential possibilities of diversity, but if we changed our manner of thinking we could change our manner of being.

In considering the opportunities that diversity presents, I urge us to consider if students' various cultural identities are valorized through education. Our focus on multicultural education must make a move from the too-benign goal of representation to a goal of valorization, one in which all stakeholders are educated to understand that increasing the value of diversity in the social order is a collective vested interest, particularly in societies that claim any kind of democratic value system. Par- 
ticularly given the social contextual backdrop and infusion into schools, how are students engaged in learning about themselves and the world around them that valorizes them through these processes? How are we equipping them with the conceptual tools and strategic muscles they need to best understand and counter the social realities of xenophobia?

Valorizing students' cultural identities will necessitate a project of actively valuing and determining with intent the manifestation of multiple cultural identities in a collective, in a school, in a classroom, and beyond. It will mean that teachers and students from the dominant culture engage with the legacies of this culture. This must happen alongside students from ethnic, gender, and class minority backgrounds who must learn about their own legacies, each of these populations uncovering these legacies where they've been silenced. This will be painful, but in the face of multicultural education that has been far too nice while legacies of colonization, slavery, and subjugation continue to pulse through our lives, a little pain is called for.

\section{WHAT VALORIZATIONS OF DIVERSITY IN EDUCATION MIGHT LOOK LIKE}

It is, in fact, because of the glaring failure of American schools to represent diversity that I believe the ground is fertile to cast aside symbolic parity as our ultimate goal and retool for valorization in education. Valorization, though, will mean an entirely different educational process for teachers, students, administrators, and parents. And it will mean work, not necessarily more work, but very different and deeper work from what schools typically include in a "foods, fashions, and festivals" approach to multiculturalism.

For example, a valorizing education would engage teachers and students in topics such as the struggle for legitimacy, xenophobia, protectionism, and global economic power that are some of the themes of Arizona's proposed restrictive legislation, mentioned in the opening section of this counterpoint essay. It would require teachers and students to research the histories that have led to these legislative moves that equate ethnic solidarity with upheaval of social order and ethnicity with illegality, connecting the similar language and tone of the Arizona legislation with the black code laws of the antebellum South. It would require that teachers and students discuss how to transact with and resist laws of exclusion, how such laws erode an inclusive social order, and what more equitable edicts and practices would promote. At heart through all of these discussions would be a goal of valorization in and through education, with all people involved with exploring their social contexts with a regard for how to nurture and grow healthy diversity. In short, it would actively engage with the social contexts of diversity. 
Valorizing diversity in education will mean that different questions must be posed, such as the following:

- Who are the students and teachers in a given classroom/school/ district?

-What are the ethnic, gender, and class demographics?

- How are these demographics reflective of the region's and nation's histories?

-What is the socioeconomic status of these populations in the local, national, and global landscape?

- What is the history of these cultures in this region, nation, and in other regions and nations in the world?

-What has been the interaction of these populations with ways of knowing?

-What contributions and social ills have been part of these intertwined histories?

- What are the most pressing challenges and opportunities for these cultural identities?

-What are the most pressing threats to their projects of healthy self-determination in a pluralistic society?

-Where are those threats coming from, and how might they be engaged?

-What are the contributions - past, potential, and current-that this cultural identity has to offer to itself and to a collective pluralistic society?

I offer these questions not as a template, model, or blueprint but as a contributing, working example of the types of social scientific questions that might mark a process of cultural valorization rather than simply a product of symbolic representation. Diversity can be seen to be an essential cornerstone from which a multifaceted, vibrant, and rigorous education arises but only if education is seen to be an emancipatory process rather than a formula for assimilationist banking of knowledge shaped by dominant groups and individuals in power. These are questions that arise when I imagine an emancipatory education for students, engaging in questions of why contexts around them are the way they are, how they might be different, what they can add to these contexts, and steps they will have to take to do so. I see teachers and students actively researching the world around them, who and what has shaped it to be as it is, and how they are active in those legacies. I can easily picture arguments; discussions; collective reading; and collective, contested writing. When I envisage these processes of valorization, I am hopeful. When I consider if schools have represented diversity, I sigh. 


\section{FURTHER READINGS AND RESOURCES}

Agar, M. (1994). Language shock: Understanding the culture of conversation. New York: William Morrow.

Banks, J. A. (1993). Multicultural education: Historical developments, dimensions, and practice. Review of Research in Education, 19, 3-49.

Deleuze, G., \& Guattari, F. (1986). Kafka: Towards a minor literature (D. Polan, Trans.). Minneapolis: University of Minnesota Press. (Original work published 1975)

Delpit, L, \& Dowdy, J. K. (2002). The skin that we speak: Thoughts on language and culture in the classroom. New York: New Press.

Eckert, P., \& McConnell-Ginet, S. (1992). Think practically and look locally: Language and gender as community-based practice. Annual Review of Anthropology, 21, 461-490.

Freire, P. (1970). Pedagogy of the oppressed. New York: Continuum.

Hanks, W. F. (1996). Language and communicative practices. Boulder, CO: Westview Press.

Kramsch, C. (1998). Language and culture. Oxford, UK: Oxford University Press.

Lave, J., \& Wenger, E. (1991). Situated learning: Legitimate peripheral participation. Cambridge, UK: Cambridge University Press.

Migration Dialogue. (1998, July) .The health and well-being of children of immigrants. Migration News [Electronic newsletter]; online at http://migration.ucdavis.edu

Moreton-Robinson, A. (2008). Writing off treaties: White possession in the United States critical whiteness studies literature. In A. Moreton-Robinson, M. Casey, \& F. Nicoll (Eds.), Transnational whiteness matters (pp. 81-96). Lanham, MD: Lexington Books.

National Black Education Agenda. (2010). For Black America, we are still a nation at risk; accessed September 1, 2010, http:/ / blackeducationnow.org/idl7.html

Nieto, S. (2008). Affirming diversity: The sociopolitical context of multicultural education (5th ed.). New York: Allyn \& Bacon.

Sarroub, L. K. (2005). All American Yemeni girls: Being Muslim in a public school. Philadelphia: University of Pennsylvania Press.

Sleeter, C. E. (2001). Preparing teachers for cultural diverse schools: Research and the overwhelming presence of whiteness. Journal of Teacher Education, 52(2), 94-106.

Suarez-Orozco, M. M. (2001). Globalization, immigration, and education: The research agenda. Harvard Educational Review, 71(3), 345-365.

Wenger, E. (1999). Communities of practice. Cambridge, UK: Cambridge University Press.

\section{COURT CASES AND STATUTES}

Prohibition of Seditious Ethnic Studies Act, Arizona House Bill 2281 (2010).

Support Our Law Enforcement and Safe Neighborhoods Act, Arizona Senate Bill 1070 (2010). 